\title{
Supercritical Extracts from Arctium lappa as a Potential Inhibitor for the Activation of Complement System
}

(ㄷ) (1) (우) $\odot$

\author{
Authors \\ Pâmela Dias Fontana1, Lorena Bavia1, Fernanda Bovo¹, Ariádine Reder C. de Souza², Marcos Lúcio Corazza², \\ lara Jose Messias-Reason ${ }^{1}$
}

\section{Affiliations}

1 Laboratory of Molecular Immunopathology, Clinical Hospital, Federal University of Paraná, Curitiba, Brazil

2 Department of Chemical Engineering, Federal University of Paraná, Curitiba, Brazil

\section{Key words}

Arctium lappa, Asteraceae, burdock, supercritical extract, classical pathway, alternative pathway, complement system, hemolysis inhibition

$\begin{array}{ll}\text { received } & 10.07 .2019 \\ \text { revised } & 28.08 .2019 \\ \text { accepted } & 02.10 .2019\end{array}$

\author{
Bibliography \\ DOI https://doi.org/10.1055/a-1025-0085 \\ Planta Med Int Open 2019; 6: e63-e69 \\ (c) Georg Thieme Verlag KG Stuttgart · New York \\ ISSN 2509-9264 \\ Correspondence \\ Dr. Lorena Bavia \\ Laboratory of Molecular Immunopathology, \\ Clinical Hospital \\ Federal University of Paraná, \\ Rua General Carneiro 181 \\ 80060-900 Curitiba \\ Parana \\ Brazil \\ Tel.: + 55/41/3360/1800 - 6537, Fax: + 55/41/3362/7598 \\ lorena.bavia@gmail.com
}

\begin{abstract}
Arctium lappa is a perennial species of the Asteraceae family originally from Europe and Asia. Considered a weed species in the southern region of Brazil, it is popularly used as a natural anti-inflammatory. The complement system is an important component of the innate immune response. However, its exacerbated activation can lead to harmful conditions like autoimmune and inflammatory disorders. Plants that inhibit the activation of complement can be a promising tool in the treatment of inflammatory diseases. Here, we evaluated the effect of $A$. lappa leaves extracts on the activation of the classical and alternative pathways of complement system. Two extracts were obtained under supercritical conditions using $\mathrm{scCO}_{2}$ with ethanol as cosolvent, at 313.15K, $15 \mathrm{MPa}$ (E1) and $25 \mathrm{MPa}$ (E2). Classical and alternative activation were evaluated using complement fixation test. Different concentrations of $A$. lappa extracts $\mathrm{E} 1$ and $\mathrm{E} 2$ showed an inhibitory effect on both complement pathways, and heparin was used as control. The $\mathrm{IC}_{50}$ of E1, E2, and heparin were 28.26, 20.12 and $92.54 \mu \mathrm{g} / \mathrm{mL}$ for classical and $26.12,27.70,27.78 \mu \mathrm{g} / \mathrm{mL}$ for the alternative pathway. Results demonstrate that $A$. lappa is a promising complementary treatment for diseases associated with complement activation.
\end{abstract}

\section{Introduction}

The plant Arctium lappa L., popularly known as Burdock, originally from Europe and Asia, is a perennial species of the Asteraceae family [1]. Burdock grows in all Brazilian territory with impressive spread. Considered a weed species in the southern region, it is popularly used for the treatment of skin injuries as well as depurative and anti-inflammatory [1, 2]. It is also consumed as infusion, decoction, or externally used as a plaster [3]. Moreover, Burdock has been used in traditional Chinese medicine and in alternative ther- apies in Europe, Asia, and North and South America [1, 2]. Several parts of this medicinal herb, including, roots, leaves, seeds, and fruits, have different scientifically proven biological activities such as hypolipidemic [4], anti-inflammatory [5, 6], antifungal [6], and antitumor properties [7]. In addition, Holetz et al. demonstrated that the extracts of $A$. lappa from plants collected in southern Brazil presented bactericidal activity against Gram-positive and Gramnegative bacteria [2]. The major active compounds isolated from A. lappa include tannin, arctigenin, arctiin, beta-eudesmol, caffeic 
acid, chlorogenic acid, inulin, trachelogenin 4, sitosterol-beta-Dglucopyran-oside, lappaol, and diarctigenin [1].

The complement system is one of the main effector branches of the innate immune response. It is constituted by more than 35 soluble or cell membrane proteins that can be activated by 3 pathways: classical, alternative, and lectin [8]. While the classical pathway is activated primarily by the recognition of immune complexes [9], the alternative starts with the spontaneous hydrolysis of the component $\mathrm{C3}$. In the lectin pathway, collectins or ficolins recognize microorganisms' carbohydrates, such as mannose and acetylated compounds, inducing its activation $[9,10]$. Once complement becomes activated, all pathways culminate with the formation of $\mathrm{C} 3$ and $\mathrm{C} 5$ convertases, leading to the production of anaphylatoxins and the membrane attack complex (MAC) [8]. As a consequence of complement activation several biological processes take place, including opsonization, phagocytosis, inflammation, leukocyte chemotaxis, release of histamine from mast cells, active leukocyte oxygen species, vasoconstriction, increased vessel permeability, platelet aggregation, and cytolysis, among others [8, 11].

It is well known that complement plays a pivotal role in host defense against pathogens. However, when its activation becomes exacerbated or uncontrolled it can lead to harmful reactions, such as those seen in autoimmune and inflammatory diseases [12]. Therefore, the modulation or inhibition of complement activation is an important target for therapies in the treatment of inflammatory diseases such as rheumatoid arthritis, systemic lupus erythematosus, atypical uremic hemolytic syndrome, Alzheimer's disease, atherosclerosis, paroxysmal nocturnal hemoglobinuria, and psoriasis, among others [13]. Despite the variety of natural products with diverse biological activities, including antiviral, analgesic, antitumor, antiallergic, anti-inflammatory, and immunomodulatory [14], natural compounds with action on complement activation are scarce [13]. Since the activation or imbalance of the complement system may be associated with several inflammatory disorders, the investigation of vegetal species that can act as inhibitors of complement is of clinical relevance.

Previous studies have identified bioactive compounds of $A$. lappa extracted by conventional extraction techniques, such as low pressure methods (Soxhlet), ultrasound, and microwave [15-17]. However, these techniques require the use of high temperatures for long extraction times, which can lead to the loss of thermosensitive compounds. In addition, there is a search for techniques considered unconventional that use lower amounts of solvents, causing less environmental impact and still presenting good yields. Thus, supercritical extraction process is the most appropriate technology to obtain extracts with low residual solvent content and low final toxic potential [18], being a great alternative as presented in previously studies $[19,20]$. Considering that the extracts of $A$. lappa leaves obtained from the mixture of supercritical carbon dioxide $\left(\mathrm{scCO}_{2}\right)$ as solvent with ethanol as cosolvent showed higher efficiency, the best conditions of overall extraction yield were obtained at $313.15 \mathrm{~K}$ and both pressures 15 and $25 \mathrm{MPa}$, and due to the great antioxidant effect that has already presented [19], these same extracts were chosen to evaluate complement modulation. Therefore, as natural products may represent a complementary approach for the treatment of inflammatory diseases associated with exacerbated complement activity, our aim is to evaluate the effect of supercritical extracts from $A$. lappa leaves on the activation of the classical and alternative pathways of complement.

\section{Results}

The extracts $\mathrm{E} 1$ and $\mathrm{E} 2$ of $A$. lappa showed inhibitory effect on the activation of both classical and alternative pathways when compared to the positive control normal human serum (NHS), as shown in > Fig. 1. The extract E1 (at concentration $183 \mu \mathrm{g} / \mathrm{mL}$ ) inhibited 36.1 and $49.1 \%$ of hemolysis by classical and alternative pathway, respectively. On the other hand, the extract E2 (at concentration $150 \mu \mathrm{g} / \mathrm{mL}$ ) inhibited 34.2 and $49.9 \%$ of hemolysis by classical and alternative pathways, respectively. The inhibitory effect of A. lappa extracts on the classical and alternative pathways was also observed at lower concentration, such as $22.88 \mu \mathrm{g} / \mathrm{mL}$ and $18.75 \mu \mathrm{g} / \mathrm{mL}$ for $\mathrm{E} 1$ and $\mathrm{E} 2$, respectively. The effect of both extracts and heparin on the complement activation was compared with the positive control of $50 \%$ of hemolysis.

In addition, the half maximal inhibitory concentration (IC50) was $28.26 \mu \mathrm{g} / \mathrm{mL}$ (confidence interval, $\mathrm{Cl}$ : 22.70-35.17; R2=0.92) for extract E1, $20.12 \mu \mathrm{g} / \mathrm{mL}$ (Cl: 13.51-29.95; R2=0.79) for extract $\mathrm{E} 2$, and $92.54 \mu \mathrm{g} / \mathrm{mL}(\mathrm{Cl}: 73.29-116.8 ; \mathrm{R} 2=0.92)$ for heparin on the activation of the classical pathway. Likewise, the IC50 was 26.12 $\mu \mathrm{g} / \mathrm{mL}(\mathrm{Cl}: 21.34-31.96 ; \mathrm{R} 2=0.93)$ for extract $\mathrm{E} 1,27.70 \mu \mathrm{g} / \mathrm{mL}(\mathrm{Cl}$ : 22.56-34.03 R2=0.92) for extract E2, and $27.78 \mu \mathrm{g} / \mathrm{mL}(\mathrm{Cl}: 22.42$ 34.42; $R 2=0.94)$ for heparin on the alternative pathway. These results indicate a dose-dependent inhibitory effect of the extracts E1 and E2 of A. lappa on both classical and alternative pathways of complement activation.

\section{Discussion}

Supercritical extracts from A. lappa leaves were able to inhibit complement activation by both classical and alternative pathways using functional assays ( $\mathbf{F i g}$. 2 ). In addition, this inhibitory effect was observed at different concentrations of $A$. lappa extracts E1 and E2. Thus, ours results showed a dose-dependent inhibitory effect for both extracts on the activation of classical and alternative pathways.

Although several biological properties of $A$. lappa have been described [1], our study is the first to describe its action as complement inhibitor. This immunomodulatory activity of $A$. lappa extracts corroborates with the anti-inflammatory actions previously reported such as activation of antioxidant enzymes and scavenging of free radicals [19,21], inhibition of inhibition of inducible nitric oxide synthase (iNOS) pathway [22], suppression of pro-inflammatory cytokine expression [22], inhibition of the nuclear factor-kappa B [23], and inhibition of NOD-like receptor pyrin domain-containing-3 (NLRP3) inflammasome activation [5].

It is noteworthy that the inhibitory effect of $A$. lappa extracts was $13 \%$ (extract E1) to $15.7 \%$ (extract E2) higher on the alternative when compared to classical pathway. This difference may be due to the inhibitory effect of the extracts on the initiating molecules, the ions involved ( $\mathrm{Ca}$ and $\mathrm{Mg}$ ), or preventing the formation of $\mathrm{C} 3$ and $\mathrm{C} 5$ convertases, which are specific for each pathway. Thus, the same extract may be more or less potent on different pathways. Furthermore, although the 3 complement pathways are triggered by different signals, the alternative pathway acts as an 

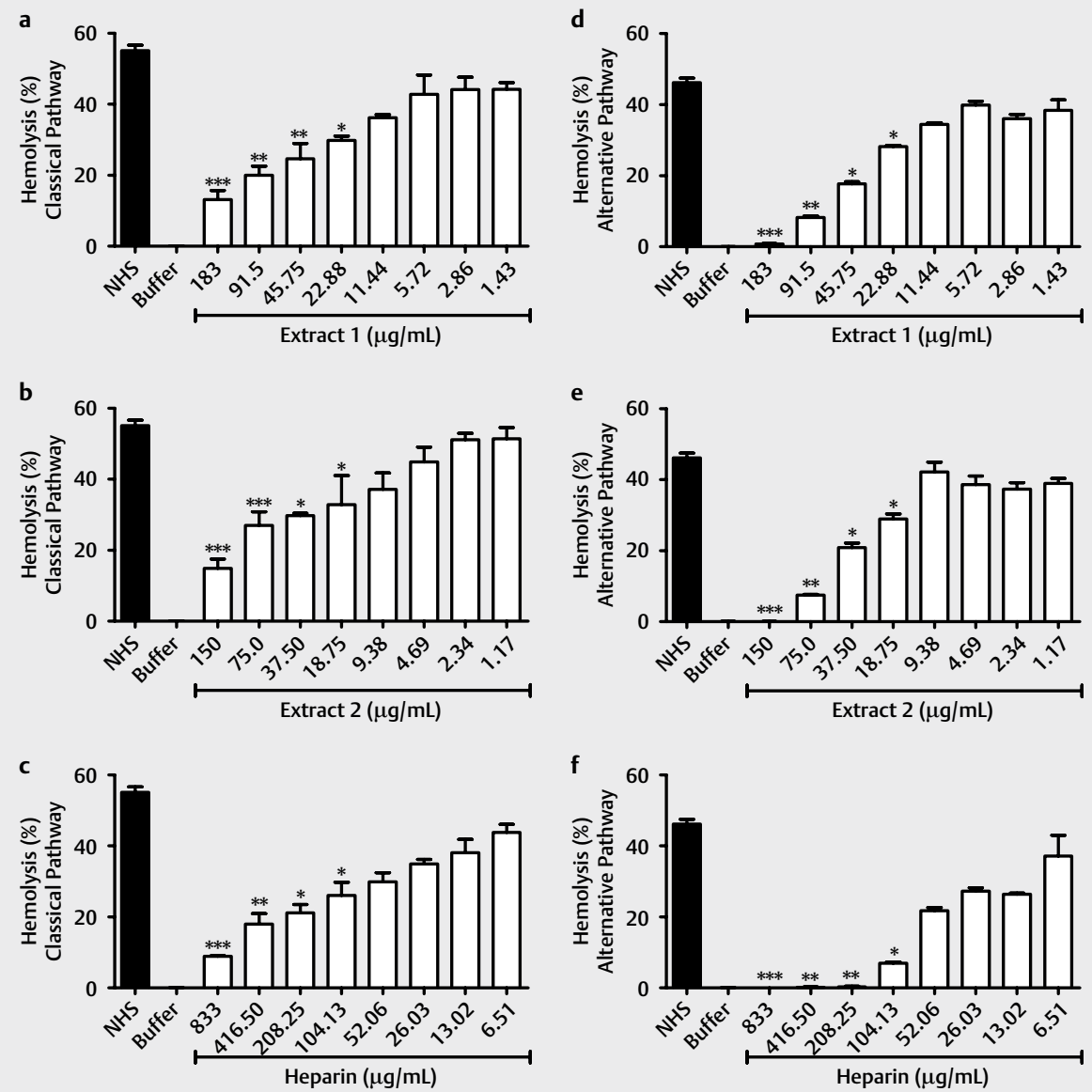

-Fig. 1 Classical and alternative pathways activation are suppressed by supercritical extracts of $A$. lappa. Activation of classical and alternative pathways is represented from $\mathbf{a}-\mathbf{c}$ and $\mathbf{d}-\mathbf{f}$, respectively. The final concentrations of both extracts evaluated and of the heparin control are represented in the x-axis. All extracts dilutions were compared with the positive control (SHN diluted to represents $50 \%$ of hemolysis) by Kruskal-Wallis with Dunn's multiple comparison as post-test $\left({ }^{* * *} \mathrm{p}<0.001,{ }^{*} \mathrm{p}<0.01\right.$, and ${ }^{*} \mathrm{p}<0.05$ ). The negative control (buffer) represents $0 \%$ hemolysis. In addition, heparin dilutions were used as control of inhibitory effect on complement activation (c and $\mathbf{f}$ ).

amplification loop of all pathways, corresponding to $80-90 \%$ of C5 activation and MAC formation when classical pathway is activated $[24,25]$. In addition, $I C_{50}$ for the extracts $\mathrm{E} 1(28.26 \mu \mathrm{g} / \mathrm{mL}$; $26.12 \mu \mathrm{g} / \mathrm{mL})$ and E2 $(20.12 \mu \mathrm{g} / \mathrm{mL} ; 27.70 \mu \mathrm{g} / \mathrm{mL})$ were lower or similar to than those found to heparin $(92.54 \mu \mathrm{g} / \mathrm{mL} ; 27.78 \mu \mathrm{g} / \mathrm{mL})$ on the activation of the classical and alternative pathway, respectively. These same extracts presented antioxidant activity with an $\mathrm{IC}_{50}$ of $424 \mu \mathrm{g} / \mathrm{mL}$ and $383 \mu \mathrm{g} / \mathrm{mL}$, for E1 and E2 [19]. These concentrations are at least 16 times higher than the concentrations found in our study, indicating a potent action of A. lappa extracts on complement.

Considering the similar results for the extracts E1 and E2 of A. lappa on complement activation assays, the different pressures and times of extraction of both samples do not appear to have affected the inhibitory properties of the extracted compounds. The predominant compounds with biological activity shared by extract $\mathrm{E} 1$ and E2 were the triterpenoids lupeol acetate and amyrin acetate and the diterpene phytol. These components have been described as anti-inflammatory substances $[26,27]$. Lupeol acetate identified in Cariniana domestica (Mart.) Miers family Lecythidaceae and Bride- lia retusa (Spreng) family Euphorbiaceae presented anti-inflammatory effect in skin inflammation and in adjuvant-induced arthritis models $[28,29]$. One of the anti-inflammatory mechanisms of lupeol acetate in arthritis models was the suppression of pro-inflammatory cytokines expression and inhibition of osteoclastogenesis [30]. Furthermore, lupeol acetate and amyrin acetate, detected as main components in extracts of Cnidoscolus chayamansa (Mc Vaugh) family Euphorbiaceae leaves, presented hepatoprotective and antiinflammatory activities in chronic models of liver damage [26]. Amyrin acetate isolated from Alstonia boonei De Wild family Apocynaceae showed significant inhibition in paw and ear edema models. It also reduced total leucocyte migration and neutrophil infiltration in vivo tests [31]. Our results corroborate the findings of Jin et al.[32], who found that amyrin acetate isolated from the leaves and twigs of Acer okamotoanum Nakai family Aceraceae exhibited a significant inhibitory effect on activation of the classical pathway. The diterpene phytol was identified as the most abundant compound of Cleome rutidosperma DC family Cleomaceae aerial essential oil and exhibited antimicrobial activity against pathogenic bacteria and fungus strain [33]. Finally, diterpene phytol was shown 


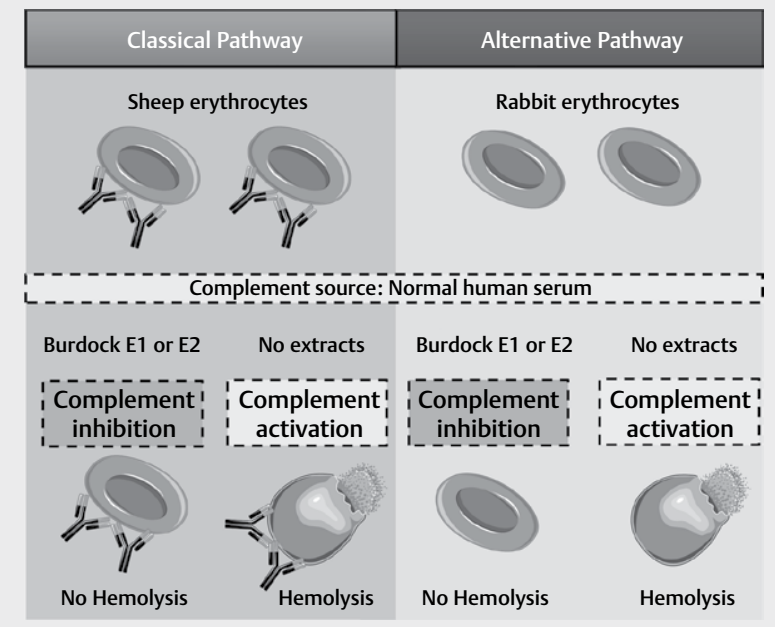

-Fig. 2 Inhibitory effect of A. lappa extracts on functional complement assays. For the hemolytic assays, different dilutions of each extract (E1 and E2) were incubated with normal human serum (as source of complement) and sensitized SE or RE for classical and alternative pathways assays, respectively. Both extracts were able to inhibit the different pathways of complement activation.

also to decrease autoimmune response in both acute and chronic phases of experimental arthritis [27], as well as phytol attenuates the inflammatory response in paw edema model by inhibiting neutrophil migration, reducing inflammatory cytokines levels and oxidative stress [34].

It is important to consider that extracts composition can be influenced by extraction process conditions. Some compounds are more sensitive than others and, depending on the time of exposition to high temperatures or pressures, can be degraded. This may justify the lack of arctigenin in our extracts, a compound identified in fractions of $A$. lappa with an important anti-inflammatory role [35-37]. However, the anti-inflammatory activity observed with $\mathrm{E} 1$ and $\mathrm{E} 2$ extracts of $A$. lappa may be due to other components, such as lupeol, amyrin, and phytol [31, 34, 38], which were also found in extracts from $A$. lappa leaves obtained by pressurized liquid extraction using aqueous ethanol [20].

The present study also demonstrated that supercritical extraction using $\mathrm{CO}_{2}$ as solvent results in extracts with important biological activities, as observed on complement activation. Moreover, the number of studies on plant compounds obtained by supercritical extraction has increased significantly in the last years, mainly due to their high applicability in health, herbal medicines, cosmetics, and nutraceutical foods [39]. The solvent $\mathrm{CO}_{2}$ present some advantages as safety, availability, low cost, nontoxicity in low concentrations, nonflammable, and noncarcinogenic. The pressure and temperatures used in supercritical extractions are relatively low and safe [40]. Nevertheless, the solubility of $\mathrm{CO}_{2}$ is limited to the nonpolar organic materials, the addition of a small amount of organic solvent, such as ethanol, may increase the solubility of polar compounds [41]. In addition, supercritical extraction is a field of interest for the pharmaceutical industry to exploit new plant species with potential medicinal use [42].
One limitation in our study was the initial concentration from both extracts, since supercritical extraction method resulted in approximately 0.8 grams ( $3.5 \%$ ) from the whole leaf weight $(22.8 \mathrm{~g}$ ) used in the beginning of the extraction process. Thus, although there is a high demand for the substitution of synthetic substances for natural resources, sustainability is based on the abundance and availability of raw materials. As future perspectives, the effects of A. lappa extracts on the activation of the lectin pathway should be also considered, as well as the identification of the components responsible for the inhibitory effect on complement.

Considering that activation of the complement plays a central role in the maintenance of inflammation, the search for substances that modulate its activation is of great concern since only Eculizumab and C1 esterase-inhibitor are options approved by the U.S. Food and Drug Administration for complement inhibition [43]. Thus, our results contribute for the better understanding of the pharmacological and medicinal properties of $A$. lappa extracts highlighting its application as a complementary treatment for inflammatory diseases associated with complement activation in future clinical studies.

\section{Materials and Methods}

This work was approved by the Human Research Ethics Committee of the Federal University of Paraná (n. 1.703.531, approved in August 30, 2016).

\section{Supercritical extracts}

The raw material used in this study comprised of the aerial parts of A. lappa. All samples used belong to a single lot harvested in July 2016 from a local property in Ivaiporã (State of Paraná, Southern, Brazil) [19]. The raw material (A. lappa leaves) presented a residual moisture of $5.97 \pm 0.02 \mathrm{wt} \%$, average particle diameter of (1.3 \pm $0.4) 10^{-3} \mathrm{~m}$, and real particle density of $1480 \mathrm{~kg} \mathrm{~m}^{-3}$, as described in a previous study by Souza et al. [19]. The extracts of $A$. lappa leaves were obtained by supercritical extraction using a bench-scale supercritical extraction unit, where $\mathrm{CO}_{2}$ was used as solvent and ethanol as cosolvent. Two extraction conditions were performed, the extract 1 (E1) was obtained under $15 \mathrm{MPa}$ in 50 min, the extract 2 (E2) under $25 \mathrm{MPa}$ in $75 \mathrm{~min}$ ( $\mathbf{F i g}$. 3). The temperature was fixed at $313.15 \mathrm{~K}$ for both extracts. The extracts were analyzed by gas chromatography-mass spectrometry (Agilent 7890A/5975C GC-MS system), and the phytochemical compounds profile were identified by Souza et al.[19] as shown in > Table 1. We used the same samples described and evaluated by Souza et al. [19] to perform the complement assays.

\section{Complement assays}

Classical and alternative complement pathways activity were assessed by complement fixation tests adapted from Alban et al. [44]. HEPES buffer solution (HEPES $10 \mathrm{mM}, 150 \mathrm{mM} \mathrm{NaCl}, \mathrm{pH}$ 7.4) (HB) supplemented with $0.11 \mathrm{mM} \mathrm{CaCl}_{2}$ and $0.5 \mathrm{mM} \mathrm{MgCl}_{2}$ (HBC), or $7 \mathrm{mM} \mathrm{MgCl}$ and $10 \mathrm{mM}$ EGTA ph 7.4 (HBA) were used to evaluate the activation of classical and alternative pathways. The extracts $\mathrm{E} 1$ and $\mathrm{E} 2$ were dissolved in the minimum amount of solvent ( $\mathrm{HB}$ with an addition of $20 \%$ DMSO) capable of promoting their complete solubilization. The final concentration obtained for the extracts E1 and 


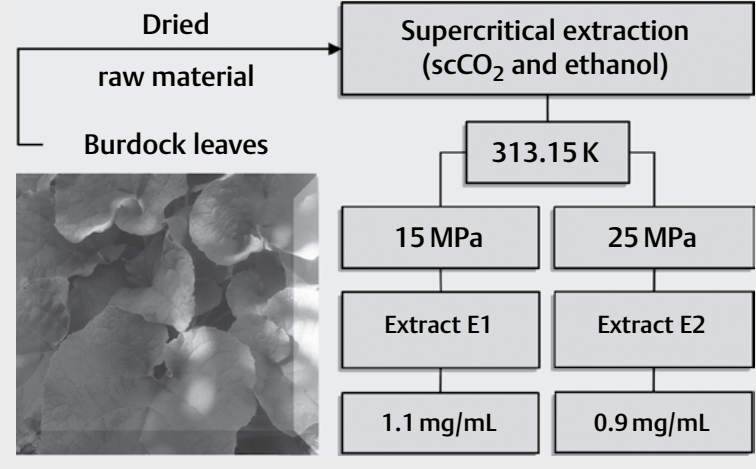

- Fig. 3 Supercritical extracts from A. lappa leaves. The extracts of A. lappa leaves were obtained by supercritical extraction using $\mathrm{CO}_{2}$ as solvent and ethanol as cosolvent. Two extraction conditions were performed: the extract 1 (E1) was obtained under $15 \mathrm{MPa}$ in $50 \mathrm{~min}$ and the extract 2 (E2) under $25 \mathrm{MPa}$ in $75 \mathrm{~min}$. The temperature was fixed at $313.15 \mathrm{~K}$ for both extracts. The extracts were dissolved in the minimum amount of solvent capable of promoting their complete solubilization.

- Table 1 Chemical composition of A. lappa leaves extracts.

\begin{tabular}{|l|c|c|}
\hline \multirow{2}{*}{ Compounds } & \multicolumn{2}{|c|}{ Relative (\%) } \\
\cline { 2 - 3 } & Extract 1 & Extract 2 \\
\hline Pyranone & 0.45 & 0.28 \\
\hline Decanoic acid & 0.62 & nd \\
\hline$\beta$-Eudesmol & 0.26 & 0.26 \\
\hline Methyl palmitate & 0.45 & 0.43 \\
\hline 1-(3-Methyl-cyclopent-2-enyl)-cyclohexene & 1.38 & 1.50 \\
\hline Hexadecanoic acid ethyl ester & 0.78 & 0.74 \\
\hline z-Phytol & 4.12 & 4.00 \\
\hline 9-Octadecenoic acid methyl ester & 0.59 & 0.57 \\
\hline Methyl stearate & 1.84 & 1.78 \\
\hline Linolenic acid ethyl ester & 0.21 & 0.21 \\
\hline 9-12-Octadecadienoic acid ethyl ester & 1.58 & 1.15 \\
\hline 3-Ethyl-5-(2'ethyl)octadecane & nd & 0.98 \\
\hline Palmitic acid $\beta$-monoglyceride & 0.49 & 0.37 \\
\hline Diisooctyl phthalate & 26.108 & 29.42 \\
\hline Methyl-7,10,13,16-docosatetraenoate & 2.01 & 1.54 \\
\hline Squalene & 3.17 & 0.75 \\
\hline Vitamin E & 1.00 & 1.02 \\
\hline Stigmasterol & 0.397 & 0.41 \\
\hline$\lambda$-sitosterol & 1.6 & 1.57 \\
\hline$\beta$-amyrin & 1.30 & 1.29 \\
\hline$\alpha$-amyrin & 0.66 & 0.40 \\
\hline 9-19-Cyclolanostane-3,7-diol & nd & 0.42 \\
\hline Stigmast-5-em-3-yl acetate & 13.69 & nd \\
\hline Amyrin acetate & 17.37 & 15.19 \\
\hline Lupeol acetate & & \\
\hline Source: adapted from Souza et al. [16]; nd: not detected. & \\
\hline & & \\
\hline
\end{tabular}

E2 were $1.1 \mathrm{mg} / \mathrm{mL}$ and $0.9 \mathrm{mg} / \mathrm{mL}$, respectively. Different dilutions of heparin were used as negative control of hemolysis [45].

\section{Normal human serum}

A pool of NHS was prepared from freshly collected peripheral blood obtained from 10 healthy volunteers at the Clinical Analysis Laboratory of Federal University of Paraná and used as complement source. The blood was maintained under refrigeration (275.15$281.15 \mathrm{~K}$ ) until total coagulation (15-30 min), centrifuged (1440 g, $20 \mathrm{~min}, 285.15 \mathrm{~K})$, and the supernatant collected, pooled, and stored at $193.15 \mathrm{~K}$ until further use.

\section{Preparation of sheep and rabbit erythrocytes suspensions} In order to analyze the activation of classical and alternative pathways, sheep (classical) and rabbit (alternative) red blood cells samples were commercially purchased (Kalifarma). Both erythrocytes were centrifuged (1500 g, $5 \mathrm{~min}$ ), the supernatant removed, and the red blood cells washed 3 times with saline $(0.9 \% \mathrm{NaCl})$. Sheep erythrocytes (SE) were also washed once with $\mathrm{HBC}$ and rabbit erythrocytes (RE) with HBA. After the last centrifugation, SE were separated and resuspended in $\mathrm{HBC}$ buffer (2.4\% vol./vol. cell suspension) and sensitized with equal volume of anti-sheep erythrocyte antibodies (1:2000, Kalifarma) for $30 \mathrm{~min}$ at $310.15 \mathrm{~K}$. Thus, suspensions of SE (1.2\% vol./vol.) and RE (2.4\% vol./vol.) were used for the classical and alternative hemolytic assays, respectively.

\section{Classical and alternative pathways hemolysis assays}

For the hemolytic assays, $20 \mu \mathrm{L}$ of the different dilutions of each extract (E1 and E2) were incubated with $50 \mu \mathrm{L}$ of NHS (equivalent to $50 \%$ of hemolysis) and $50 \mu \mathrm{L}$ of sensitized SE or RE for classical and alternative pathways assays, respectively, for $30 \mathrm{~min}$ at $310.15 \mathrm{~K}$. In addition, the following controls were included in the classical and alternative hemolysis assays: (a) $70 \mu \mathrm{L}$ of ultra-pure water and $50 \mu \mathrm{L}$ of SE or RE previously sensitized, corresponding to $100 \%$ hemolysis, (b) $20 \mu \mathrm{L}$ of HBC or HBA, $50 \mu \mathrm{L}$ of NHS and $50 \mu \mathrm{L}$ of SE or RE, corresponding $0 \%$ hemolysis, and (c) $20 \mu \mathrm{L}$ of $\mathrm{HBC}$ or $\mathrm{HBA}, 50 \mu \mathrm{L}$ of $\mathrm{NHS}$ and $50 \mu \mathrm{L}$ of SE or RE, corresponding to $50 \%$ hemolysis. Samples and controls were centrifuged at $1500 \mathrm{~g}$ for $5 \mathrm{~min}$ (Centrifuge 5430, Eppendorf). The supernatant was transferred to a 96 -well flat bottom plate and the absorbance read at $405 \mathrm{~nm}$ in a spectrophotometer (Biotek Instruments ELx800). All the extracts were previously tested for hemolytic activity in the same concentrations used in all experiments. None of them presented detectable hemolysis, being both considered nonhemolytic. All the experiments were executed in triplicate. The results were expressed as the percentage of hemolysis obtained compared with control samples adapted from Alban et al. [44].

\section{Statistical analysis}

All experiments were performed in triplicate and the results expressed as mean and standard deviation. Data were analyzed by Kruskal Wallis with Dunn's multiple comparison as post-test $\left({ }^{* * *} \mathrm{p}<0.001,{ }^{*}{ }^{*} \mathrm{p}<0.01\right.$ and $\left.{ }^{*} \mathrm{p}<0.05\right)$ and the $\mathrm{IC}_{50}$ was calculated using GraphPad Prism 5 software. 


\section{Acknowledgments}

The authors are grateful to CNPq and CAPES for financial support and scholarships.

\section{Conflict of Interest}

The authors declare no conflict of interest.

\section{References}

[1] Chan YS, Cheng LN, Wu JH, Chan E, Kwan YW, Lee SM, Leung GP, Yu $\mathrm{PH}$, Chan SW. A review of the pharmacological effects of Arctium lappa (burdock). Inflammopharmacology 2011; 19: 245-254

[2] Holetz FB, Pessini GL, Sanches NR, Cortez DA, Nakamura CV, Filho BP. Screening of some plants used in the Brazilian folk medicine for the treatment of infectious diseases. Mem Inst Oswaldo Cruz 2002; 97: 1027-1031

[3] Jeelani S, Khuroo MA. Triterpenoids from Arctium lappa. Nat Prod Res 2012; 26: 654-658

[4] Taher M, Hussain DAA, Hasan HF, Fahmi ZM, Luaibi OK, Ali MG. Hypolipidemic effect of caffeic acid isolated from Arctium lappa cultivated in Iraq, in hyperlipidemic rat model. Iraqi J Pharm Sci 2015; 24: 7

[5] Kim YK, Koppula S, Shim DW, In E], Kwak SB, Kim MK, Yu SH, Lee KH, Kang TB. Inhibitory effect and mechanism of Arctium lappa extract on NLRP3 inflammasome activation. Evid Based Complement Alternat Med 2018; 2018: 6346734

[6] Fierascu RC, Georgiev MI, Fierascu I, Ungureanu C, Avramescu SM, Ortan A, Georgescu MI, Sutan AN, Zanfirescu A, Dinu-Pirvu CE. and others Mitodepressive, antioxidant, antifungal and anti-inflammatory effects of wild-growing Romanian native Arctium lappa L. (Asteraceae) and Veronica persica Poiret (Plantaginaceae). Food Chem Toxicol 2018; 111: 44-52

[7] Lou C, Zhu Z, Zhao Y, Zhu R, Zhao H. Arctigenin, a lignan from Arctium lappa L., inhibits metastasis of human breast cancer cells through the downregulation of MMP-2/-9 and heparanase in MDA-MB-231 cells. Oncol Rep 2017; 37: 179-184

[8] Ricklin D, Hajishengallis G, Yang K, Lambris JD. Complement: A key system for immune surveillance and homeostasis. Nat Immunol 2010; 11: 785-797

[9] Wallis R, Mitchell DA, Schmid R, Schwaeble W], Keeble AH. Paths reunited: Initiation of the classical and lectin pathways of complement activation. Immunobiology 2010; 215: 1-11

[10] Evans-Osses I, de Messias-Reason I, Ramirez MI. The emerging role of complement lectin pathway in trypanosomatids: Molecular bases in activation, genetic deficiencies, susceptibility to infection, and complement system-based therapeutics. Sci World J 2013; 2013: 1-12

[11] Gasque P. Complement: A unique innate immune sensor for danger signals. Mol Immunol 2004; 41: 1089-1098

[12] Ricklin D, Lambris JD. Complement in immune and inflammatory disorders: Pathophysiological mechanisms. J Immunol 2013; 190: 3831-3838

[13] Wagner E, Frank MM. Therapeutic potential of complement modulation. Nat Rev Drug Discov 2010; 9: 43-56

[14] Newman D], Cragg GM. Natural products as sources of new drugs over the 30 years from 1981 to 2010. J Nat Prod 2012; 75: 311-335

[15] Jiang YY, Yu J, Li YB, Wang L, Hu L, Zhang L, Zhou YH. Extraction and antioxidant activities of polysaccharides from roots of Arctium lappa $L$. Int | Biol Macromol 2019; 123: 531-538
[16] Zhao J, Evangelopoulos D, Bhakta S, Gray Al, Seidel V. Antitubercular activity of Arctium lappa and Tussilago farfara extracts and constituents. J Ethnopharmacol 2014; 155: 796-800

[17] Lou Z, Wang H, Zhu S, Chen S, Zhang M, Wang Z. Ionic liquids based simultaneous ultrasonic and microwave assisted extraction of phenolic compounds from burdock leaves. Anal Chim Acta 2012; 716: 28-33

[18] Sánchez-Camargo AP, Mendiola JA, Ibáñez I, Herrero M. Supercritical fluid extraction. In: Reedijk J, ed. Reference Module in Chemistry, Molecular Sciences and Chemical Engineering. Waltham: Elsevier; 2014: 1-17

[19] de Souza ARC, Guedes AR, Rodriguez JMF, Bombardelli MCM, Corazza ML. Extraction of Arctium lappa leaves using supercritical $\mathrm{CO} 2$ + ethanol: Kinetics, chemical composition, and bioactivity assessments. I Supercrit Fluids 2018; 140: 137-146

[20] Souza ARCd, Stefanov S, Bombardelli MCM, Corazza ML, Stateva RP. Assessment of composition and biological activity of Arctium lappa leaves extracts obtained with pressurized liquid and supercritical CO2 extraction. J Supercrit Fluids 2019; 152: 1-10

[21] Lin CC, Lu JM, Yang J], Chuang SC, Ujiie T. Anti-inflammatory and radical scavenge effects of Arctium lappa. Am J Chin Med 1996; 24: 127-137

[22] Namdar Ahmadabad H, Behnamfar M, Nezafat Firizi M, Saghayan S, Taghasi F, Abbaspur A. Comparison of the immunomodulatory properties of root and leaves of Arctium lappa (Burdock) in vitro. Zahedan J Res Med Sci 2017; 19: e12965

[23] Sohn EH, Jang SA, Joo H, Park S, Kang SC, Lee CH, Kim SY. Anti-allergic and anti-inflammatory effects of butanol extract from Arctium Lappa L. Clin Mol Allergy 2011; 9: 4

[24] Harboe M, Mollnes TE. The alternative complement pathway revisited. J Cell Mol Med 2008; 12: 1074-1084

[25] Harboe M, Ulvund G, Vien L, Fung M, Mollnes TE. The quantitative role of alternative pathway amplification in classical pathway induced terminal complement activation. Clin Exp Immunol 2004; 138 : 439-446

[26] Pérez-González MZ, Siordia-Reyes AG, Damián-Nava P, HernándezOrtega S, Macías-Rubalcava ML, Jiménez-Arellanes MA. Hepatoprotective and anti-inflammatory activities of the Cnidoscolus chayamansa (Mc Vaugh) leaf extract in chronic models. Evid Based Complement Alternat Med 2018; 2018: 3896517

[27] Hultqvist M, Olofsson P, Gelderman KA, Holmberg J, Holmdahl R. A new arthritis therapy with oxidative burst inducers. PLoS Med 2006; 3: e348

[28] Milani GB, Camponogara C, Piana M, Silva CR, Oliveira SM. Cariniana domestica fruit peels present topical anti-inflammatory efficacy in a mouse model of skin inflammation. Naunyn Schmiedebergs Arch Pharmacol 2019; 392: 513-528

[29] Tatiya AU, Saluja AK, Kalaskar MG, Surana SJ, Patil PH. Evaluation of analgesic and anti-inflammatory activity of Bridelia retusa (Spreng) bark. J Tradit Complement Med 2017; 7: 441-451

[30] Wang WH, Chuang HY, Chen CH, Chen WK, Hwang J]. Lupeol acetate ameliorates collagen-induced arthritis and osteoclastogenesis of mice through improvement of microenvironment. Biomed Pharmacother 2016; 79: 231-240

[31] Okoye NN, Ajaghaku DL, Okeke HN, Ilodigwe EE, Nworu CS, Okoye FB. beta-Amyrin and alpha-amyrin acetate isolated from the stem bark of Alstonia boonei display profound anti-inflammatory activity. Pharm Biol 2014; 52: 1478-1486

[32] Jin W, Min BS, Lee J, Thuong PT, Lee HK, Song K, Seong YH, Bae K. Isolation of constituents and anti-complement activity from Acer okamotoanum. Arch Pharm Res 2007; 30: 172-176

[33] McNeil M], Porter RBR, Rainford L, Dunbar O, Francis S, Laurieri N, Delgoda R. Chemical composition and biological activities of the essential oil from Cleome rutidosperma DC. Fitoterapia 2018; 129: 191-197 
[34] Silva RO, Sousa FB, Damasceno SR, Carvalho NS, Silva VG, Oliveira FR, Sousa DP, Aragão KS, Barbosa AL, Freitas RM. and others Phytol, a diterpene alcohol, inhibits the inflammatory response by reducing cytokine production and oxidative stress. Fundam Clin Pharmacol 2014; 28: 455-464

[35] Gao Q, Yang M, Zuo Z. Overview of the anti-inflammatory effects, pharmacokinetic properties and clinical efficacies of arctigenin and arctiin from Arctium lappa L. Acta Pharmacol Sin 2018; 39: 787-801

[36] Zhao F, Wang L, Liu K. In vitro anti-inflammatory effects of arctigenin, a lignan from Arctium lappa L., through inhibition on iNOS pathway. J Ethnopharmacol 2009; 122: 457-462

[37] Wu X, Yang Y, Dou Y, Ye J, Bian D, Wei Z, Tong B, Kong L, Xia Y, Dai Y. Arctigenin but not arctiin acts as the major effective constituent of Arctium lappa $L$. fruit for attenuating colonic inflammatory response induced by dextran sulfate sodium in mice. Int Immunopharmacol 2014; 23: 505-515

[38] Saleem M. Lupeol, a novel anti-inflammatory and anti-cancer dietary triterpene. Cancer Lett 2009; 285: 109-115

[39] de Melo MMR, Silvestre AJD, Silva CM. Supercritical fluid extraction of vegetable matrices: Applications, trends and future perspectives of a convincing green technology. J Supercrit Fluids 2014; 92: 115-176
[40] Danh LT, Mammucari R, Truong P, Foster N. Response surface method applied to supercritical carbon dioxide extraction of Vetiveria zizanioides essential oil. Chem Eng J 2009; 155: 617-626

[41] Ruckenstein E, Shulgin I. Entrainer effect in supercritical mixtures. Fluid Phase Equilib 2001; 180: 345-359

[42] KHC Baser, Buchbauer G. eds. Handbook of Essential Oils: Science, Technology, and Applications.Boca Raton: CRC Press, Taylor \& Francis Group, LLC; 2010: 1-994

[43] Gaya da Costa M, Poppelaars F, Berger SP, Daha MR, Seelen MA. The lectin pathway in renal disease: Old concept and new insights. Nephrol Dial Transplant 2018; 33: 2073-2079

[44] Alban S, Classen B, Brunner G, Blaschek W. Differentiation between the complement modulating effects of an arabinogalactan-protein from Echinacea purpurea and heparin. Planta Med 2002; 68: $1118-1124$

[45] Logue GL. Effect of heparin on complement activation and lysis of paroxysmal nocturnal hemoglobinuria $(\mathrm{PNH})$ red cells. Blood 1977; 50: 239-247 